\title{
STUDIES OF TOTAL PULMONARY CAPACITY AND ITS SUBDIVISIONS. VII. OBSERVATIONS DURING THE ACUTE RESPIRATORY DISTRESS OF BRON- CHIAL ASTHMA AND FOLLOWING THE ADMINISTRATION OF EPINEPHRINE ${ }^{1}$
}

\author{
BY ALBERTO HURTADO AND NOLAN L. KALTREIDER \\ (From the Department of Medicine of the School of Medicine and Dentistry of the \\ University of Rochester and the Medical Clinic of the Strong Memorial and \\ Rochester Municipal Hospitals, Rochester, New York)
}

(Received for publication August 6, 1934)

In the hope that new light might be thrown on the functional pathology of asthma and the mode of action of epinephrine the total pulmonary capacity and its subdivisions have been measured during the acute stage of bronchial asthma, and the observations repeated soon after the administration of this drug.

\section{METHODS}

The methods used in the determination of the total pulmonary capacity and its subdivisions, the nomenclature adopted, and the normal findings, both in males and in females, have been fully presented in previous papers (1), (2). The only modification in the technique previously described is that the determinations were made with the patients in the sitting posture, because some were disturbed by severe orthopnea. In five cases the pulmonary capacity was determined during the acute respiratory distress of the asthmatic attack, and again a few minutes after the subcutaneous administration of epinephrine, when the paroxysm had been relieved. In a sixth case the second determination was made two days later, after the acute symptoms had subsided; in this case no epinephrine had been administered.

\section{CASE ABSTRACTS}

A brief clinical summary of the cases studied is presented:

Case 1. Male, aged 42 years. History of hay fever and asthmatic attacks for six and four years respectively. Skin tests indicated sensitiviness to ragweed, feathers, cat dander and dog dander. No dyspnea or cough in the intervals between the attacks. Chest not emphysematous in appearance. Roentgenograph : marked increase in the linear markings, with a flaring of the ribs.

1 The expenses of this investigation were defrayed from a fund contributed by the Corning Glass Company, The Eastman Kodak Company, The American Grinding Wheel Manufacturing Association, The American Laundry Machinery Company, the Gleason Works, the Symington Company and the Pfaudler Company. 
The first determination of pulmonary capacity was made during a severe attack of bronchial asthma with marked respiratory distress, cyanosis, audible wheezing, prolongation of the expiration, and numerous musical râles over both lungs. The second observation was carried out 12 minutes after the subcutaneous injection of $0.75 \mathrm{cc}$. of epinephrine $(1: 1000)$. At this time there was complete relief from the symptoms; the patient felt no respiratory discomfort; cyanosis had disappeared and examination of the chest revealed disappearance of the signs previously noted.

Case 2. Male, aged 40 years. History of hay fever and asthma of five and three years' duration respectively. Skin tests showed hypersensitiveness to ragweed. Dyspnea of moderate severity and moderate cough were noted between the attacks. The chest was not emphysematous in appearance but was hyperresonant on percussion. Roentgenograph revealed marked increase in linear markings with prominent hilar shadows; slight diffuse fibrosis and sclerosis of the aorta. The pulmonary capacity was determined during a very mild attack of asthma, when the patient complained of "heavy breathing." On examination there was a marked prolongation of the expiration and numerous musical râles heard over both lungs. The second observation was made 10 minutes after the subcutaneous injection of $0.75 \mathrm{cc}$. of epinephrine $(1: 1000)$. At this time the patient reported that he was not conscious of his breathing. On examination the breath sounds had assumed a normal character and all râles had disappeared.

Case 3. Male, aged 37 years. History of asthma of 12 years' duration. The cause was not determined but probably the attacks were related to chronic respiratory infection. Severe dyspnea $(+++)$ and cough occurred between the attacks. The chest was markedly emphysematous and hyperresonant on percussion. Roentgenograph: gross accentuation of the lung markings with diffuse beading; low position of the diaphragm. The pulmonary capacity was determined during a moderately severe attack of asthma. Auscultation revealed a prolongation of expiration with audible wheezing and numerous musical râles over both lungs. The observation was repeated 12 minutes after the subcutaneous injection of $0.75 \mathrm{cc}$. of epinephrine $(1: 1000)$ which caused a marked amelioration of the respiratory distress and cessation of the audible wheezing and of the musical râles.

Case 4. Male, 44 years. History of asthmatic attacks related to physical activity for a period of two years. Severe dyspnea $(+++)$ and cough persisted in the intervals between attacks. The chest was slightly emphysematous in appearance and the percussion note hyperresonant. Roentgenograph: accentuation of the lung markings with increased radiability of the lungs. The first observation of the pulmonary capacity was made several minutes after the patient had exercised, and during a severe typical asthmatic paroxysm. The patient was very cyanotic and dyspneic with audible wheezing; auscultation of the lungs revealed a marked prolongation of the expiration and abundant sibilant and musical râles. The determination of pulmonary capacity was repeated 15 minutes after the subcutaneous administration of $0.5 \mathrm{cc}$. of epinephrine $(1: 1000)$ which caused a complete relief of the respiratory distress, resumption of the normal character of the breath sounds, and cessation of the râles.

Case 5. Female, 22 years. Pregnancy of four months' duration. History of asthmatic attacks for a period of two years, for which no allergic basis was found. Moderate dyspnea $(++)$ and cough were observed during the last two years. The chest was emphysematous in appearance and the percussion note hyperresonant. Roentgenograph: increased linear markings were noted, espe- 
cially at the hilar regions. The first observation of the pulmonary capacity was made during an attack of asthma in which there was moderate respiratory distress, audible wheezing, a marked prolongation of the expiration, and numerous musical râles over both lungs. The pulmonary capacity was determined again 20 minutes after $0.75 \mathrm{cc}$. of epinephrine $(1: 1000)$ had been administered subcutaneously, resulting in a marked amelioration of the subjective symptoms, although auscultation still revealed some prolongation of the expiration and a few scattered musical râles.

Case 6. Male, 38 years. History of severe asthmatic attacks of 15 years' duration, possibly related to hypersensitiveness to ragweed and to a chronic upper-respiratory infection. Moderate dyspnea $(++)$ and cough were noted during these years. The chest was emphysematous in appearance and hyperresonant on percussion. Roentgenograph : gross accentuation of the lung markings with flaring of the rib cage; pleural thickening at the right base. The pulmonary capacity was determined while the patient was in a mild attack of asthma, in which there was slight respiratory distress, but audible wheezing; prolongation of the expiration and sibilant and musical râles on auscultation. A second observation was carried out two days later when all the above symptoms had subsided. No epinephrine was administered.

\section{Determination of the pulmonary capacity}

The results of the determinations of pulmonary capacity during the acute respiratory distress of bronchial asthma, and a few minutes after the subcutaneous administration of epinephrine in the five cases studied are presented in Table $I$ and in Figure 1. During the asthmatic attack

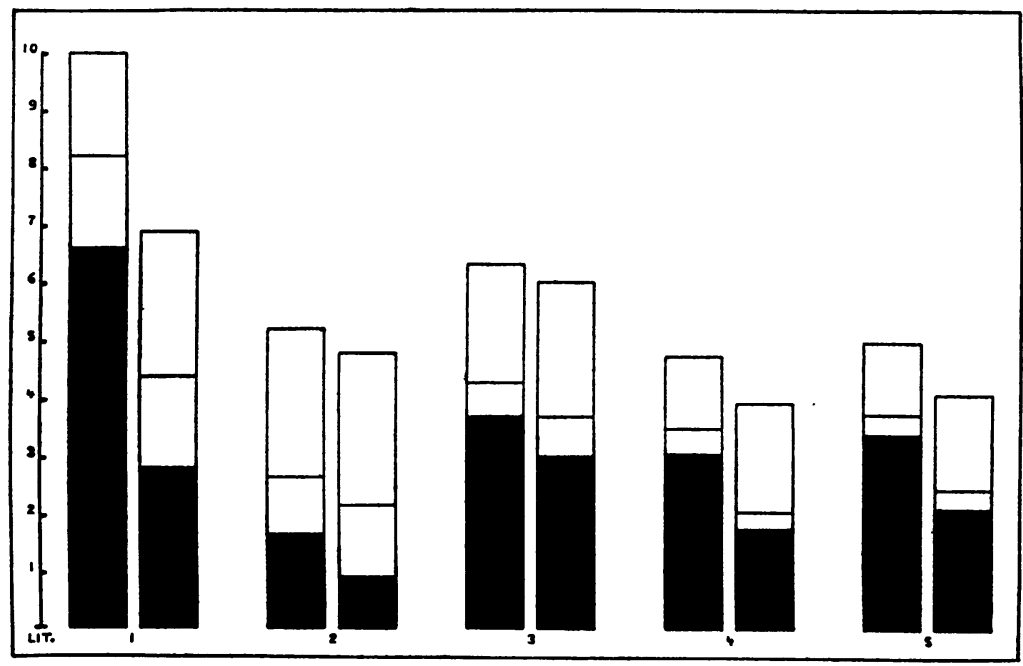

Fig. 1. Pulmonary Capacity During the Acute Respiratory Distress of Bronchial Asthma (Left Column) and Soon After Its Relief by the Subcutaneous Administration of Epinephrine (Right Column) in Five CAsEs.

The black area in each column represents the residual air; the white space above is the vital capacity. The line dividing the vital capacity is the mid capacity level. 


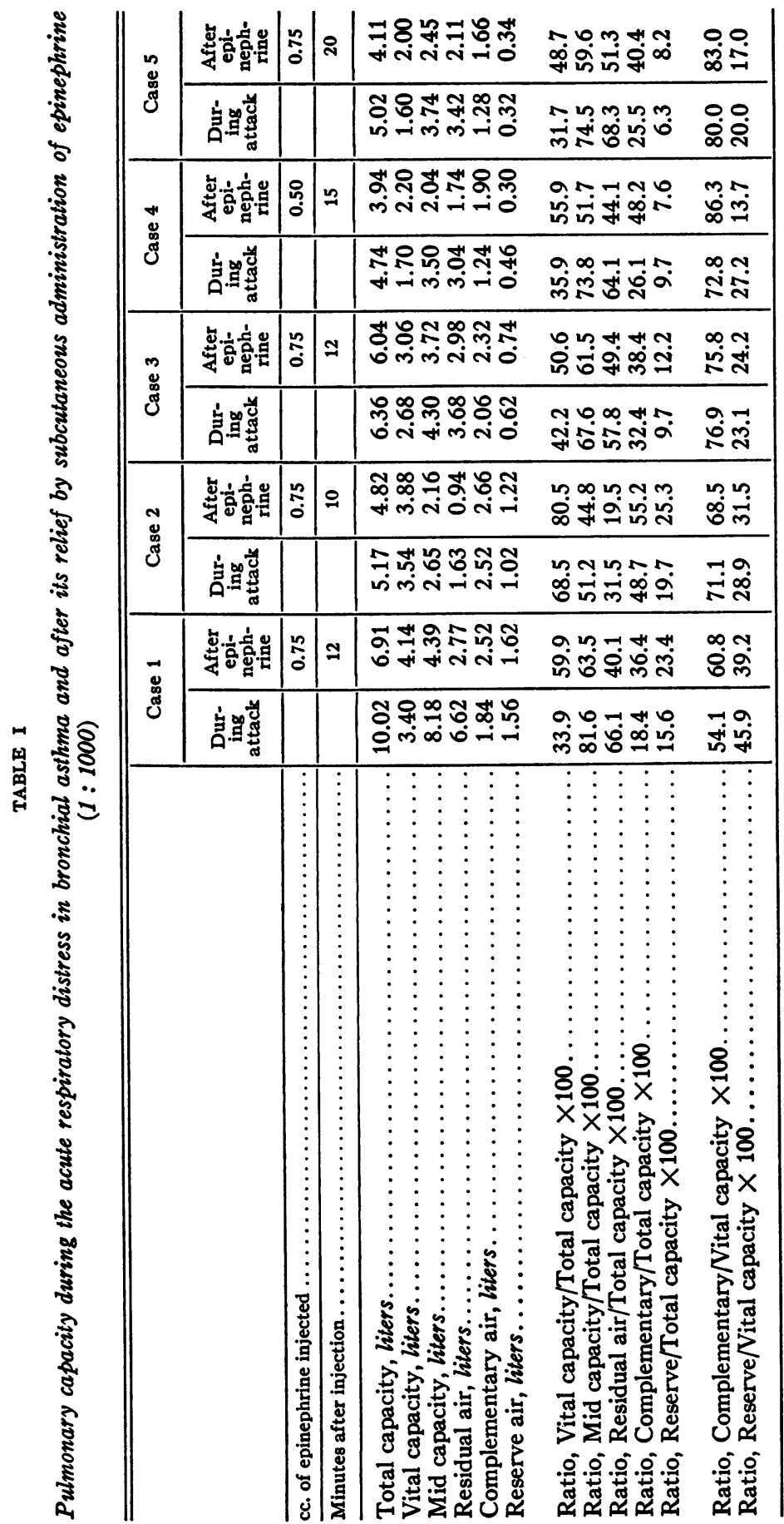


there was a decrease of the vital capacity together with a marked increase in the mid capacity and residual volume. With the exception of Case 2 these alterations were quite pronounced, and in Case 1 the increase in the residual air was of such magnitude as to give the highest total pulmonary capacity (10.02 liters) which we have yet observed. The relative values (total capacity $=100$ per cent) were correspondingly altered. There was a marked decrease of the ratio of vital to total capacity with a proportional
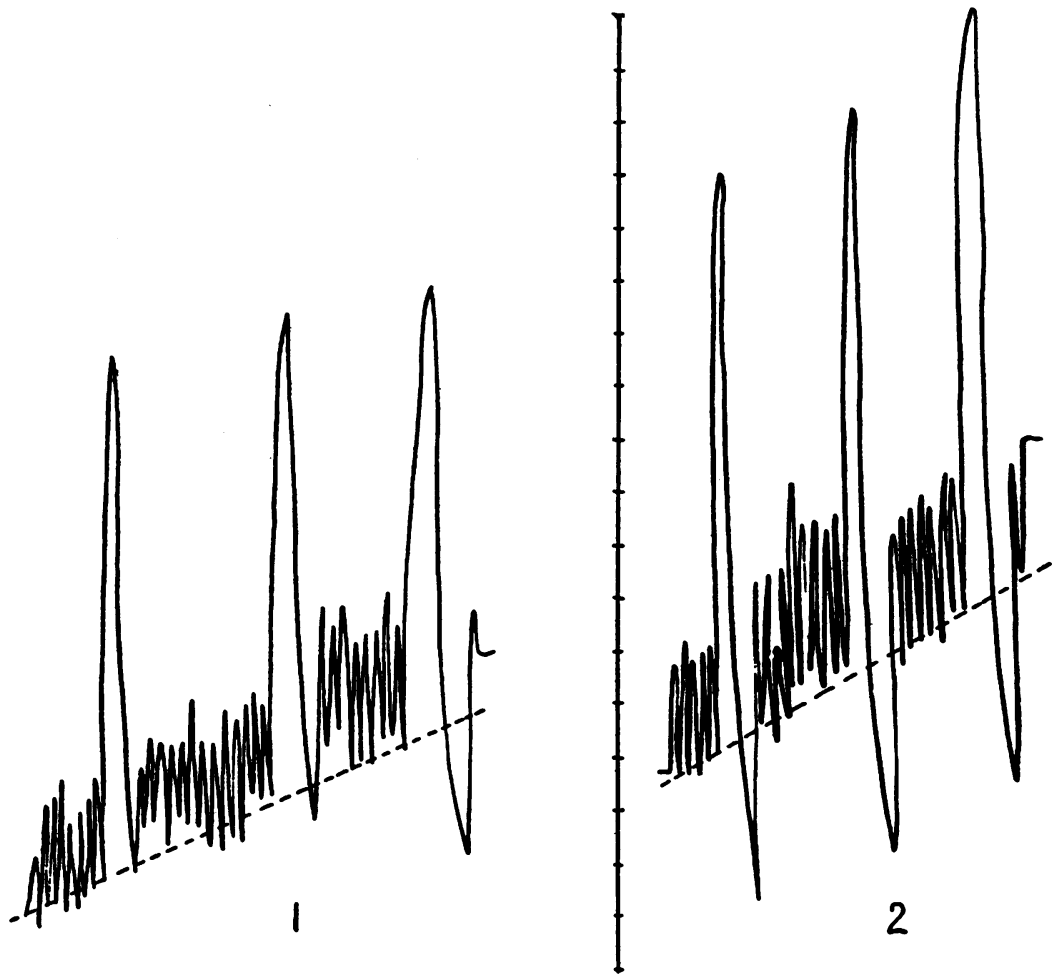

Fig. 2. Vital Capacity Tracings from Case 3 During the Acute Respiratory Distress of Bronchial Asthma (1) and Soon After Its Relief Following the Subcutaneous Administration of Epinephrine (2).

Notice the disappearance of the reserve air in two of the vital capacity determinations before epinephrine and the increase in the complementary and reserve volumes after epinephrine was administered.

Divisions on the scale correspond to $200 \mathrm{cc}$. Broken line underlying the tidal breathing is the mid capacity level.

increase in the ratios of the mid capacity and residual air to total capacity. In all cases but one (Case 2), the abnormalities in these ratios were well beyond the normal limits of variation so that they resembled the values observed by us in severe cases of pulmonary emphysema with marked respiratory disability (3). Of the components of vital capacity, the comple- 
mentary air appeared most affected, with a consequent relative increase in the reserve volume. We have already mentioned that in all cases the subcutaneous administration of epinephrine produced, after a few minutes, a marked amelioration or disappearance of the respiratory distress experienced by these patients. The changes in pulmonary capacity which accompanied this symptomatic improvement were quite strikingly constant. A definite increase in the vital capacity occurred together with a more marked decrease in the mid capacity and residual air, so that the relative values of these components approximated the normal limits of variation, although never reaching strictly normal values except in Case 2. The total capacity decreased markedly in Case 1 and in a lesser degree in the other patients. The changes which were observed in the vital capacity, and its two components: the complementary and reserve air, as the result of the administration of epinephrine may be appreciated in Figure 2 (Case 3 ). From Table II it may be seen that when a second injection of epine-

TABLE II

Pulmonary capacity before and after the subcutaneous injection of epinephrine in a case of bronchial asthma with no acute respiratory distress at the time of administration

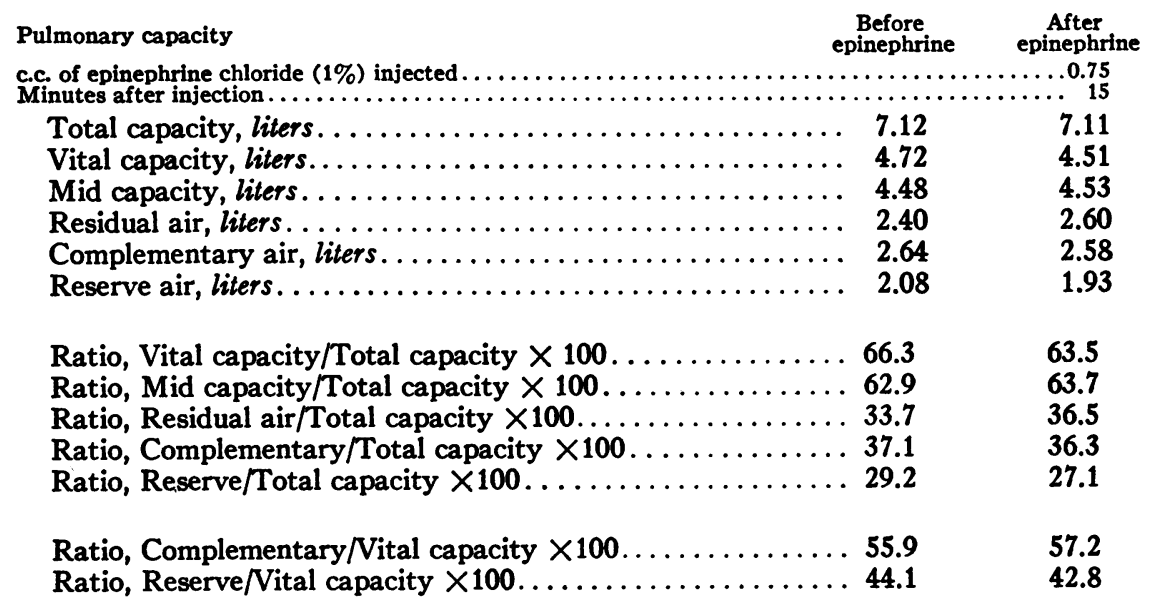

phrine was given to one of our patients (Case 1) a few days later, during an interval between the asthmatic attacks when no respiratory distress was present, it did not produce any significant alteration in the pulmonary capacity. In Case 6 (Figure 3) in which no epinephrine was given, a comparison of pulmonary capacities determined during the asthmatic attack and two days later when the respiratory distress had subsided reveals the same relative changes as those which occurred in patients to whom epinephrine was given. 


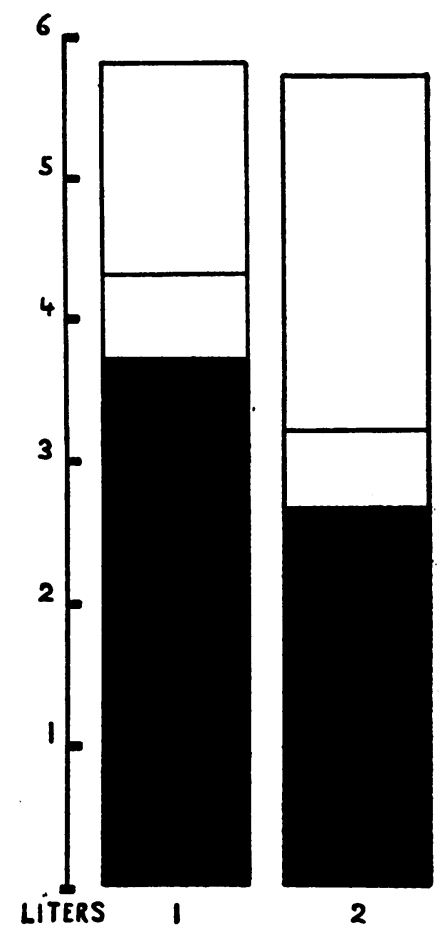

Fig. 3. Pulmonary Capacity During the Respiratory Distress of Bronchial asthma (Left Column) and Two Days later When the Acute Symptoms Had Subsided (Right Colume).

No epinephrine was administered in this case.

TABLE III

Pulmonary capacity during and after the acute respiratory distress of bronchial asthma (No epinephrine administered)

$\begin{array}{lll}\text { Pulmonary capacity } & \begin{array}{c}\text { During } \\ \text { attack }\end{array} & \begin{array}{c}\text { After } \\ \text { attack }\end{array}\end{array}$

Total capacity, liters. .................. $5.78 \quad 5.72$

Vital capacity, liters..................... $2.08 \quad 3.06$

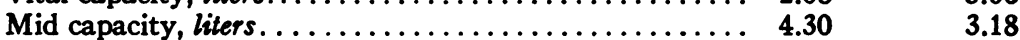

Residual air, liters. .................... $3.70 \quad 2.66$

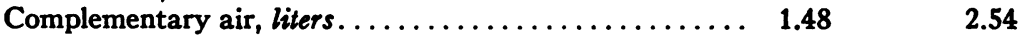

Reserve air, liters. ..................... $0.60 \quad 0.52$

Ratio, Vital capacity/Total capacity $\times 100 \ldots \ldots \ldots \ldots 36.0 \quad \mathbf{5 3 . 5}$

Ratio, Mid capacity/Total capacity $\times 100 \ldots \ldots \ldots \ldots \ldots 74.3 \quad 55.5$

Ratio, Residual air/Total capacity $\times 100 \ldots \ldots \ldots \ldots \ldots 64.0 \ldots \ldots$

Ratio, Complementary/Total capacity $\times 100 \ldots \ldots \ldots \ldots 25.5$

Ratio, Reserve/Total capacity $\times 100 \ldots \ldots \ldots \ldots \ldots \ldots 10.3$

Ratio, Complementary/Vital capacity $\times 100 \ldots \ldots \ldots \ldots 71.1 \quad 83.0$

Ratio, Reserve/Vital capacity $\times 100 \ldots \ldots \ldots \ldots \ldots \ldots 28.9 \quad 17.0$ 


\section{DISCUSSION}

There are few observations in the literature in regard to the determination of the total pulmonary capacity and its subdivisions during the severe respiratory distress of bronchial asthma. We have been unable to find any reference to the changes which occur after the administration of epinephrine in these cases. Means (4) in his monograph on "Dyspnea" refers to investigations made in his own clinic in which an increase of the vital capacity and of the ventilation per minute was observed following the administration of epinephrine in asthmatic attacks. Anthony (5), in 1930, observed changes in pulmonary capacity similar to those mentioned in this communication. Lippelt (6) by narrowing the afferent tube of the Knipping respirator, and thus simulating the bronchial obstruction to expiration as in asthma, produced in healthy subjects an increase in the mid capacity and residual air and a decrease in the complementary volume. Warren (7) in 1913 made orthodiagraphic studies in a case of bronchial asthma and found that the area of the lung fields (measured by means of a planimeter) gradually became smaller as the frequency of the attacks diminished. He also observed that as the patient improved there was an increase in the excursion of the diaphragm. In one of our patients (Case 1 ), studied fluoroscopically, the maximal excursion of the diaphragm was measured during the asthmatic attack and again after the administration of epinephrine. An increase of almost two centimeters was seen in the second observation.

These observations of the pulmonary capacity during the asthmatic attack aid in understanding the mechanism of the acute respiratory distress experienced by these patients. The marked increase in the residual air and the simultaneous decrease of the vital capacity represent an unfavorable condition for efficient alveolar ventilation. The situation corresponds to that of an extreme case of emphysema, the severe respiratory disability of which has been correlated closely with the degree of change in these two components of the pulmonary capacity. It is also possible that the rapidity with which these changes occur in an asthmatic paroxysm tends to increase the severity of the distress, since there is little time for compensatory adjustments to such an abnormal condition.

Without entering into the evidence as to whether the underlying anatomical and functional mechanism in bronchial asthma is that of bronchiolar edema or bronchiolar spasm or both, it appears to us quite probable that the latter mechanism plays a prominent part. According to Macklin (8) the point of constriction is probably situated in the terminal bronchioles. The narrowing of these structures interferes with expiration, causing a distension of the alveoli and subsequent lessened pulmonary elasticity limiting at the same time the volume of air which may be taken into the lungs in a deep inspiration. Hence the asthmatic patient not only has a 
greater amount of alveolar air to be ventilated, but he also suffers from a mechanical limitation of his ability to increase the ventilation per minute. It may be assumed that the action of epinephrine widens the bronchioles, either by relief of their constriction or by diminution of edema of their mucosa, thus permitting rapid and marked decrease in the residual volume, increase in the vital capacity, and consequently more efficient alveolar ventilation.

The consistent character of the changes observed following the administration of epinephrine in these cases of bronchial asthma suggested to us the desirability of studying the effect of acetyl-beta-methylcholin, the broncho-constricting action of which has been demonstrated by Comroe and Starr (9). Starr, Elsom and Reisinger (10), and Starr (11) observed the production of typical asthmatic attacks after the administration of this drug. Our observations are as follows: An intramuscular injection of $30 \mathrm{mgm}$. was given to a healthy young adult, and three and a half minutes later the vital capacity was found to be 3.12 liters as compared with a previous value of 3.98 liters. In another young normal subject the vital capacity was decreased from 4.10 to 3.40 liters by the administration of $15 \mathrm{mgm}$. of the drug. The diminution in both of these cases affected chiefly the complementary air. A sense of substernal constriction and difficult breathing were noted in both instances. Attempts to measure the residual air after the administration of this drug were not successful because of the rapidity with which its action disappeared. In both instances, however, a definite lowering of the mid capacity level was noted in the respiratory tracings, about three to four minutes after the onset of the typical effects elicited by the drug (sweating, lowering of the blood pressure, etc.). This change in the tracing probably indicates that an increase in the mid capacity had occurred.

\section{SUMMARY AND CONCLUSIONS}

In five cases measurements of the total pulmonary capacity and of its subdivisions were made during the acute respiratory distress of bronchial asthma, and soon after relief of this following the subcutaneous administration of epinephrine. In another case the pulmonary capacity was determined after gradual spontaneous recovery.

Observations were made also of the effect of acetyl-beta-methylcholin on the vital capacity of two normal subjects. These observations led to the following conclusions:

1. During the acute respiratory distress of bronchial asthma there is a decrease in the absolute and relative value of the vital capacity, and a marked increase in the mid capacity and residual air.

- 2. A few minutes after the administration of epinephrine the vital capacity increases and there is a marked decrease in the mid capacity and 
residual air. These changes are accompanied by an amelioration or disappearance of the respiratory distress.

3. The alterations in the pulmonary capacity throw light on the functional pathology of the asthmatic attack, and upon the therapeutic action of epinephrine. Following the administration of acetyl-beta-methylcholin to two healthy subjects, a moderate decrease in vital capacity was observed. This was probably accompanied by an increase in the mid capacity, as indicated by the change in the graphic tracing of the respirations. Accurate measurement of the residual air and mid capacity was impossible on account of the evanescent action of acetyl-beta-methylcholin.

\section{BIBLIOGRAPHY}

1. Hurtado, A., and Boller, C., Studies of total pulmonary capacity and its subdivisions. I. Normal, absolute and relative values. J. Clin. Invest., 1933, 12, 793.

2. Hurtado, A., Fray, W. W., Kaltreider, N. L., and Brooks, W. D. W., Studies of total pulmonary capacity and its subdivisions. V. Normal values in female subjects. J. Clin. Invest., 1934, 13, 169.

3. Hurtado, A., Kaltreider, N. L., Fray, W. W., Brooks, W. D. W., and McCann, W. S., Studies of total pulmonary capacity and its subdivisions. VI. Observations on cases of obstructive pulmonary emphysema. J. Clin. Invest., 1934, 13,

4. Means, J. H., Dyspnea. Medicine, 1924, 3, 309.

5. Anthony, A. J., Untersuchungen über Lungenvolumina und Lungenventilation. Deutsches Arch. f. klin. Med., 1930, 167, 129.

6. Lippelt, H., Einfluss der Stenosenatmung auf Lungenventilation und Lungenvolumina beim Gesunden. Beitr. z. klin. d. Tuberk., 1932, 81, 520.

7. Warren, L. F., An orthodiagraphic study of a case of bronchial asthma. Am. J. M. Sc., 1913, 146, 711.

8. Macklin, C. C., The musculature of the bronchi and lungs. Physiol. Rev., $1929,9,1$.

9. Comroe, J. H., Jr., and Starr, I., Jr., Further studies on the pharmacology of acetyl-beta-methylcholin and ethyl esther of beta-methylcholin. J. Pharmacol. and Exper. Therap., 1933, 49, 283.

10. Starr, I., Elsom, K. A., and Reisinger, J. A., Acetyl-beta-methylcholin. I. The action on normal persons with a note on the action of ethyl ether of beta-methylcholin. Am. J. M. Sc., 1933, 186, 313.

11. Starr, I., Acetyl-beta-methylcholin. III. Its action on paroxysmal tachycardia and peripheral vascular disease with a discussion of its action in other conditions. Am. J. M. Sc., 1933, 186, 330. 